Archives de sciences sociales des religions

112 | octobre-décembre 2000

Âme et corps : conceptions de la personne

\title{
LANGLOIS (Claude), Les Dernières paroles de Thérèse de Lisieux. Aimer, être aimée et revenir sur la terre
}

Paris, Éditions Salvator, 2000, 173 p. (coll. «Pierres d'angle»)

Jacques Maître

\section{OpenEdition}

Édition électronique

URL : http://journals.openedition.org/assr/20320

DOI : $10.4000 /$ assr. 20320

ISSN : $1777-5825$

Éditeur

Éditions de l'EHESS

Édition imprimée

Date de publication : 31 décembre 2000

Pagination : 102-103

ISBN : 2-222-96698-1

ISSN : 0335-5985

Référence électronique

Jacques Maître, "LANGLOIS (Claude), Les Dernières paroles de Thérèse de Lisieux. Aimer, être aimée et revenir sur la terre », Archives de sciences sociales des religions [En ligne], 112 | octobre-décembre 2000, document 112.30, mis en ligne le 19 août 2009, consulté le 21 septembre 2020. URL : http:// journals.openedition.org/assr/20320 ; DOI : https://doi.org/10.4000/assr.20320

Ce document a été généré automatiquement le 21 septembre 2020.

(C) Archives de sciences sociales des religions 


\section{LANGLOIS (Claude), Les Dernières paroles de Thérèse de Lisieux. Aimer, être aimée et revenir sur la terre}

Paris, Éditions Salvator, 2000, 173 p. (coll. «Pierres d'angle »)

Jacques Maître

\section{RÉFÉRENCE}

LANGLOIS (Claude), Les Dernières paroles de Thérèse de Lisieux. Aimer, être aimée et revenir sur la terre, Paris, Éditions Salvator, 2000, 173 p. (coll. « Pierres d'angle »)

Depuis quelques années, les recherches scientifiques sur Thérèse de Lisieux se sont concentrées pour une bonne part sur les propos de Thérèse recueillis par ses sœurs dans la période où la petite carmélite se mourait de tuberculose. Par leur nature même, ces paroles ne nous sont connues qu'à travers des témoignages; elles se trouvent regroupées pour l'essentiel dans les Derniers entretiens. Les polémiques autour de l'authenticité des textes publiés sont d'autant plus vives que les enjeux théologiques surdéterminent les opinions. CL. se place sur un tout autre terrain épistémologique : «Je n'entre pour ma part dans aucune visée théologique; au point de vue méthodologique, comme historien, je dois, pour comprendre Thérèse, partir non de son actualité mais de son altérité, tant comme personne que comme écrivain... ou comme malade réduite à sa seule parole. Je ne cherche pas à rendre intelligible sa doctrine, je situe ma démarche à un niveau beaucoup plus modeste; ailleurs, savoir ce qu'elle a vraiment écrit ; ici, entendre ce qu'elle a effectivement dit... (p. 34) ».

2 Il commence avec une rigueur exemplaire par examiner en historien très averti la fiabilité des témoins, au premier rang desquels figurent Pauline Martin (en religion Mère Agnès) et Céline Martin (en religion sœur Geneviève), toutes deux aînées de Thérèse. Laissant en suspens les " longues paroles » sur la Vierge et les propos prêtés à Thérèse quant à la publication éventuelle de ses écrits, CL. arrive à repérer des passages 
interpolés (par exemple sur la conscience qu'aurait eu Thérèse de sa capacité de mener après sa mort une action apostolique d'envergure...), mais il établit également que les textes dont nous disposons comprennent beaucoup d'éléments solides, comme le montre notamment leur adéquation avec la chronologie des événements attestés par ailleurs. Il faut démêler ce qui constitue le noyau authentique et les habillages dus à Pauline, Céline ou d'autres. S'étant équipé d'un tel «mode d'emploi », l'auteur peut construire un ensemble d'interprétations pondérées et approfondies, comme l'indique d'entrée de jeu le sous-titre de l'ouvrage.

3 Sans polémique passionnelle et sans refuser de tirer au clair les désaccords, CL. fournit ici une contribution essentielle à la recherche. Il met à la disposition de tous un instrument de travail qui manquait, il expose une démarche exemplaire d'historien et il renouvelle des questionnements jusqu'ici empesés par les idées reçues. Un tel ouvrage constitue une rampe de lancement pour les «spécialistes" du domaine et leur indique même des directions à explorer. Quand il critique à l'occasion certains de mes propres résultats, je peux mesurer ce qu'a d'enrichissant un aussi libre débat entre chercheurs qui se soumettent à une seule loi : militer dans l'« Internationale des travailleurs de la preuve » (Gaston Bachelard). 